\title{
Safety and Efficacy of Inflatable Penile Prostheses for the Treatment of Erectile Dysfunction: Evidence to Date
}

\author{
Vinson M Wang, Laurence A Levine \\ Division of Urology, Rush University Medical Center, Chicago, IL, USA \\ Correspondence: Laurence A Levine, Email drlevine@hotmail.com
}

\begin{abstract}
Erectile dysfunction (ED) is a common problem, and prevalence rates are expected to rise as life expectancy increases worldwide. In more severe cases of ED, penile prosthesis implantation has been an excellent option for patients. Over the past few decades, significant design improvements have been made to the penile prosthesis and modifications to surgical technique to improve clinical outcomes. The purpose of this review is to summarize the safety and efficacy of FDA-approved penile implants in the US market. Design modifications have greatly improved the safety and reliability of the implant. Development of improved surgical techniques has decreased intraoperative injuries and reservoir-related complications. With its high overall satisfaction rates and low risk of complications, the inflatable penile prosthesis remains an excellent option for patients with erectile dysfunction.
\end{abstract}

Keywords: inflatable penile prosthesis, erectile dysfunction, prosthesis complications, prosthesis satisfaction

\section{Introduction}

Erectile dysfunction is a common disorder with roughly half of men between the ages of 40 to 70 experiencing some degree of erectile dysfunction. ${ }^{1}$ Prevalence of ED increases with age, diabetes, hypertension, cardiovascular disease, smoking status along with many other factors. ${ }^{1,2}$ Current treatment of ED commonly involves the use of oral phosphodiesterase type 5 inhibitors (PDE5i) as first-line therapy. In more severe cases of ED that are refractory to oral regimens, patients may require intracavernosal injections (ICI) of vasodilators. Patients who do not respond well to ICI or who do not desire to pursue ICI may be offered a penile prosthesis to create an artificial erection. Although implantable penile prostheses have gone through significant iterations over the past century, the principal characteristics of the device have not changed over the years - a penile prosthesis should produce an artificial erection that would mimic a natural erection in terms of rigidity and not interfere with sensation, ejaculation, spontaneity, orgasm, and urination.

Historically, the first documented penile prosthesis dates to the 16th century when Dr. Ambroise Pare inserted a wooden pipe following a traumatic penile amputation. ${ }^{3}$ However, its intent was to facilitate urination rather than sexual activity. In 1936, Dr. Nikolaj Bogoraz utilized autologous rib cartilage to achieve an artificial erection. ${ }^{4}$ Rib cartilage unfortunately was temporary as it was resorbed by the body over time. Drs. Goodwin and Scott reported the use of acrylic prostheses in 1952, which allowed for a more permanent solution. ${ }^{5}$ In the 1960 s, polyethylene and silicone rods were developed and experience showed that placing the prosthesis under the tunica albuginea created a more rigid erection that was less likely to erode than implants placed outside of the tunica albuginea. ${ }^{6}$ In 1973, Dr. Scott developed the contemporary 3-piece inflatable penile prosthesis (IPP), with two inflatable silicone cylinders, a reservoir, and a pump that allowed the transfer of fluid from the reservoir to the cylinders to produce an artificial erection. ${ }^{7}$ Over the years, significant design developments were made to improve durability, rigidity, safety, and the patient experience. This review will focus on FDA-approved devices in the United States and their safety and efficacy. 


\section{Safety}

\section{Risk of Intraoperative Injuries}

While penile prosthesis placement is generally safe and well tolerated, intraoperative complications can occur (Table 1). ${ }^{8}$ Proximal or distal corporal perforations can occur typically at the time of dilation. A proximal corporal perforation can be addressed by placement of a sling through rear tip extenders to prevent implant migration. ${ }^{9}$ A distal corporal perforation requires careful inspection of urethral injury. Urethral injury at the time of penile prosthesis placement is rare but historically was managed with abortion of the prosthesis procedure as an urethral injury would increase the risk of implant infection. ${ }^{9}$ Small urethral injuries may heal without repair, and a catheter may be placed. Larger urethral injuries may require primary closure. ${ }^{10}$ In a recent survey of surgeon practices, $55 \%$ of surgeons would abort the procedure after distal urethral injury, while $45 \%$ would continue the procedure with either unilateral or bilateral insertion of cylinders. ${ }^{11}$ In the setting of distal corporal perforation with crossover but without urethral injury or extrusion, the trajectory of the tract can be altered and re-dilated. The cylinders can then be re-placed in the appropriate corporal tunnels.

Traditionally, the implant reservoir is placed in the space of Retzius through the floor of the external inguinal ring. Intraoperative reservoir complications are rare but can result in bladder, bowel, or vascular injury. ${ }^{12}$ Furthermore, the reservoir may have been placed ectopically or could erode into the bladder/surrounding structures. Post-operatively, reservoir herniation and auto-inflation of the cylinders may occur. ${ }^{12,13}$ In rare situations, the reservoir can cause compression of the external iliac vein resulting in venous compression syndrome. Patients with a history of pelvic surgery such as radical prostatectomy or cystectomy are at higher risk of reservoir complications due to the altered space of Retzius and increased pelvic scarring. Patients with previous pelvic radiation may also have poorer tissue quality and be more prone to complications such as erosions. In patients with a history of unilateral inguinal hernia repair or renal transplantation, the reservoir can be placed on the contralateral side to avoid the patients' previous surgeries.

In patients with a higher risk of reservoir complications, surgeons can elect to place a 2-piece implant or opt for an ectopic reservoir location. The 2-piece Ambicor prosthesis was designed to eliminate the need for an external reservoir by integrating the fluid reservoir into the proximal aspect of the pair of cylinders itself. Although data comparing the Ambicor prosthesis with 3-piece implants are limited, the existing literature shows high patient satisfaction rates. ${ }^{14-16}$ Early studies of its reliability showed a $2.3 \%$ mechanical failure rate with a mean follow-up of 43 months. ${ }^{14}$ Fluid leak at the proximal end of the cylinders was one of the most common reasons for mechanical failure before the device was redesigned in $1998 .{ }^{17}$ Despite these revisions, cylinder aneurysms at the deflation flex point continue to be a cause of mechanical failure. ${ }^{18} \mathrm{~A}$ systematic review of penile prosthesis found higher survival rates among malleable and 2-piece implants compared to 3-piece implants. ${ }^{19}$ Although the Ambicor prosthesis eliminates the need to place a separate reservoir, it has a less natural deflated appearance compared to the 3-piece implant. Thus, the Ambicor 2-piece implant is a less popular choice and accounts for less than $5 \%$ of penile implants today. ${ }^{17}$ However, the Ambicor prosthesis is still considered an excellent option for certain patients with a history of pelvic surgery or radiation.

Although the Ambicor prosthesis is a good option in patients with higher risk of reservoir complications, ectopic reservoir placement is another option that allows for a 3-piece IPP placement without the risks associated with space of Retzius placement. Most commonly, an ectopic reservoir is placed between transversalis fascia and transversus abdominis or rectus abdominis. In obese patients, the reservoir can even be placed anterior to the abdominal muscles with

Table I Summary of Intra-Operative Complications

\begin{tabular}{|l|l|}
\hline Complication & Management \\
\hline Proximal Corporal perforation & Support via rear tip extender sling \\
\hline Distal Corporal perforation/urethral injury & Abort vs unilateral/bilateral placement of cylinders ${ }^{\prime \prime}$ \\
\hline Corporal crossover & Re-dilate corpora and re-direct cylinders \\
\hline Bowel, bladder, vascular injury & Repair injured structure \pm abort implant \\
\hline
\end{tabular}


good outcomes as the increased adipose tissues can hide the reservoir well. ${ }^{12,20,21}$ The disadvantage of an ectopic reservoir placement is that the reservoir may be visible, and the patient may be able to feel the reservoir. A low profile reservoir design was introduced to decrease reservoir visibility in submuscular reservoir placements. Common complications related to ectopic reservoir placement include reservoir leakage, abdominal muscular pain, folding of the reservoir itself, and torsion of reservoir tubing resulting in blockage of fluid transport. ${ }^{22}$ Overall reservoir-related complications requiring revision were similar between standard space of Retzius placement $(1.3 \%)$ compared to ectopic placement $(2.0 \%){ }^{22}$ However, ectopic reservoir placement remains a reliable option and may be considered in patients with a history of pelvic surgeries. For surgeons who do not prefer ectopic reservoir placement, the Levine Jorgenson scissors technique allows for safe entry into the space of Retzius. ${ }^{23}$ This technique involves the use of Jorgenson scissors, which are placed through an external inguinal ring just superior to the pubis. The curved tips of the Jorgenson scissors are pointed away from the bowel and bladder, allowing for controlled perforation through the transversalis fascia. Reservoirrelated complication rates were similar between patients with a history of prior pelvic surgery vs the virgin pelvis group with this technique.

\section{Risk of Infection}

Prosthetic infection is perhaps the most feared complication as this could lead to sepsis requiring explant of the prosthesis. Reported rates of post-operative infection can range between $0.5 \%$ and $5 \%$ depending on antibiotic regimen, implant, surgical technique and patient demographics. ${ }^{24-27}$ Evolution of prosthesis design has also reduced the risk of infection with the impregnation of minocycline and rifampin directly onto the silicone of American Medical System (AMS) implants in 2000 and the coating of a hydrophilic substance that allows the absorption of antibiotic solutions onto the Titan implant in 2002. ${ }^{28}$ A retrospective review by Carson in 2004 found reduced infection rates in virgin implant placements when using AMS 700 series implant coated with InhibiZone (0.68\%) compared to those without antibiotic coating $(1.61 \%)$ at 180 days follow-up. ${ }^{26}$ Similarly, Wolter et al found that by coating the polyvinylpyrrolidone coated Titan prosthesis had lower rates of infection (1.06\%) compared to the Alpha-1 non-coated prosthesis (2.07\%) at 1 year follow-up. ${ }^{29}$ Furthermore, Wilson et al found reduced infection rates when using InhibiZone implants not only in the virgin setting but also in implant revision, when a washout was also performed. ${ }^{30}$ Wilson et al also noted that there were no post-operative infections in 223 patients without diabetes compared to one post-operative infection in 83 (1\%) patients with diabetes. Infection rates were higher in the revision setting, where 4 post-operative infections were seen in 123 cases (3\%). In one of the largest retrospective studies, Carson et al reported long-term data with up to 7.7 year follow-up of over 39,000 patients who underwent penile prosthesis placement. ${ }^{31}$ They reported a $1.1 \%$ infection-related revision rate in antibiotic-coated implants compared to $2.5 \%$ revision rate in non-coated implants. Furthermore, the incorporation of the "no-touch" technique decreased infection rates to $0.46 \% .{ }^{24}$ Currently, there are no universally accepted guidelines for peri-operative IV antibiotics and intraoperative antibiotic irrigation/prosthesis coating regimens that would minimize infections. Thus, antibiotic regimens should be chosen by the surgeon based on hospital-specific antibiograms. Other precautions that can reduce infection rates include a ten-minute betadine scrub, limiting through traffic within the operating room, and frequent re-gloving throughout the operation.

Despite the numerous advancements in prosthesis antibiotic coating and protocols taken, prosthesis infections still occur. Patients with an infected implant may present with fever, persistent penile pain, erythema, and fluctuance. ${ }^{32}$ Patients with signs of sepsis require immediate treatment with IV antibiotics and fluids. Infected implants must be either completely removed or replaced following extensive washout utilizing Mulcahy's salvage approach. ${ }^{33}$ The Mulcahy salvage approach involves the initial removal of all implant parts, followed by aggressive wound irrigation with a series of kanamycin/bacitracin, hydrogen peroxide, betadine, vancomycin, and gentamicin. After washout and changing of gloves, a new penile prosthesis is replaced.

\section{Risk of Mechanical Malfunction}

Mechanical failure of the implant typically involves leakage of saline from the system due to a crack or tear in the cylinders, tubing or reservoir. This results in malfunction of the penile prosthesis and inability to achieve an artificial erection. The risk of mechanical failure increases with time and usage. A study of 438 consecutive patients who received 
the AMS $700 \mathrm{CX}$ showed that 82 patients (20.6\%) experienced mechanical failure with a median follow-up of 82 months. ${ }^{34}$ Mechanical survival rates of the penile prosthesis were $97.6 \%, 93.2 \%$, and $78.2 \%$ at 3,5 , and 10 years followup, respectively. Over the years, design improvements to penile prosthesis implants have further improved mechanical reliability. In 1992, the Mentor Alpha 1 prosthesis added pump reinforcement that improved 10 years mechanical survival to $88.6 \% .{ }^{35}$ And in 2001 , AMS added a parylene coating to the cylinders that increased 3 years mechanical survival to $97.9 \% .{ }^{35}$ Another study showed an overall penile prosthesis survival rate of $90.8 \%$ and $85.0 \%$ at 5 and 10 years followup. ${ }^{36}$ The most common cause of mechanical failure was fluid loss in $75 \%$ of cases. In addition to fluid loss from the implant system, other mechanical malfunctions involve tubing kinks, pump/valve cycling issues, and auto-inflation of the prosthesis. However, prosthesis design improvements have significantly reduced rates of mechanical aberrations.

In the setting of mechanical failure, revision surgery can be performed if the patient wishes to be sexually active (Table 2). If an obvious defect in the prosthesis can be identified and isolated, the affected component can be exchanged. The entire implant may also be removed and replaced, especially if the original device was implanted many years ago (typically after 3-7 years) and prone to additional mechanical failures. ${ }^{37}$ As it may be challenging to remove the reservoir, the reservoir may be drained and retained. ${ }^{38}$

\section{Safety Considerations in Following Pelvic Surgery}

Patients commonly experience erectile dysfunction following radical prostatectomy, cystectomy, abdominoperineal resection, and other pelvic surgeries. Despite advances in nerve-sparing radical prostatectomy, many patients still cannot achieve erections hard enough for sexual penetration postoperatively. ${ }^{39}$ Similarly, significant neurovascular trauma can occur following radical cystectomy and many patients experience erectile dysfunction despite alternative nerve sparing approaches. ${ }^{40,41}$ Due to potentially serious nerve injury, many patients may be refractory to oral PDE5i/ICI and may be candidates for penile prosthesis placement. As radical prostatectomy and cystectomy involve incising the peritoneum, the traditional space of Retzius may be obliterated. While some surgeons may prefer two-piece prosthesis placement in postprostatectomy patients, retropubic placement of the reservoir was not associated with increased complications. ${ }^{22}$ In a retrospective study, use of the Levine Jorgenson scissors technique allowed safe placement of the reservoir into the space of Retzius even in patients with prior radical prostatectomy and inguinal hernia repair. ${ }^{23}$ This approach was designed to enter the space of Retzius with the curved tips of the scissors pointing away from the bladder, bowel, and vessels, thereby reducing the likelihood of injury to these structures. If attempts to access the space of Retzius with the Levine Jorgenson scissors approach are met with resistance, then ectopic reservoir placement is recommended. Reservoir-related complication rates were similar between patients with a history of prior pelvic surgery vs the virgin pelvis group. ${ }^{12,23}$ In another study of 115 post-prostatectomy patients, a retropubic reservoir was successfully placed without any bladder or iliac vessel injury in any patients. ${ }^{42}$ More than $90 \%$ of devices were free of mechanical failure at 5 years of follow-up. While two-piece penile prosthesis remains a good option for post-prostatectomy patients, three-piece implants with traditional or ectopic reservoir placements can also be safely placed. ${ }^{39,43}$

Similarly, in patients with ED following radical cystectomy, options for penile prosthesis include malleable, twopiece, and three-piece implants. Following radical cystectomy, significant scarring, translocation of bowel and the presence of urinary diversion or orthotopic bladder make reservoir placement in the traditional space unwise.

Table 2 Summary of Post-Operative Complications

\begin{tabular}{|l|l|l|}
\hline Complication & Incidence & Management \\
\hline Implant infection $^{24,31}$ & $0.5-1.1 \%$ & Salvage vs delayed reimplantation \\
\hline Mechanical failure $^{34,36}$ & $15-20 \%$ at 10 years & Replace or revise implant \\
\hline Reservoir erosion/herniation $^{12}$ & $<1 \%$ & Replace or reposition reservoir \\
\hline Autoinflation $^{13}$ & $2-3 \%$ & Capsulotomy or repositioning of reservoir \\
\hline Hematoma $^{8}$ & $0.2-5 \%$ & Bedrest and compressive dressings, exploration is rarely required \\
\hline
\end{tabular}


However, ectopic placement of the reservoir can be placed in the lateral retroperitoneum through a counter-incision or in the pre-peritoneal space. ${ }^{44-46}$ In a retrospective review of 80 patients who had 3-piece implants placed following radical cystectomy, there were no instances of bowel, urinary diversion, or vascular injury with a lateral retroperitoneal reservoir placement. ${ }^{44}$ Of these 80 patients, 3 patients required revision of pump location, and 2 patients required revision for mechanical failure with a mean follow-up of 54 months. No associations were found between infection (5\%) and type of urinary diversion, radiation, chemotherapy, or presence of artificial urinary sphincter (AUS). In patients with a continent cutaneous diversion or ileal conduit, the reservoir is typically placed contralateral to the stoma in order to decrease the risk of injury to the urinary tract if revision became necessary. ${ }^{46}$ In patients with orthotopic neobladders, reservoirs can be placed on either side depending on surgeon preference.

\section{Safety in Transgender Patients}

In female-to-male gender-affirming surgeries with neophallus construction, the placement of a penile prosthesis represents a last step to providing functional ability to the neophallus. ${ }^{47}$ Tactile and erogenous sensations develop in the neophallus within 4 to 6 months. ${ }^{48}$ Unperceived chronic pressure on the neophallus can increase the risk of prosthesis extrusion. Thus, the development of tactile sensation is protective, and many patients and surgeons opt to wait at least a year before prosthesis implantation. In one study, the mean time between neophallus construction and prosthesis placement was 3.5 years. ${ }^{49}$ The first reported prosthesis placement in a neophallus was described in $1978 .{ }^{50}$ In the 1990s, a modified single-cylinder 2-piece Mentor GFS, then later the Ambicor prosthesis was utilized in the neophallus, which provided excellent axial rigidity and avoided a separate reservoir. ${ }^{48}$ A polytetrafluoroethylene windsock was fashioned as a pseudo-tunic and secured to the pubis to prevent cylinder migration. A single cylinder was utilized due to the fact that the largest Ambicor cylinder provides excellent axial rigidity. Furthermore, placement of 2 cylinders would require additional dissection, increasing the risk of injuring the neophallic neurovascular supply and compromising penile sensation. Zuckerman et al reported outcomes of semirigid and 3 piece inflatable prostheses in patients with total phallic construction. ${ }^{51}$ At 5.5 -month follow-up, 5 implants $(23 \%)$ were explanted due to infection or erosion. This is quite high compared to the complication rate in cis-males, likely due to the fact that the neophallus in trans-males does not have a corpora cavernosa for prosthesis placement. Furthermore, gender-affirming surgery typically involves multiple surgeries, which can compromise vascularization and subsequently tissue/wound healing abilities following prosthesis implantation. Hoebeke et al reported on the outcomes of 129 female to male neophallus prosthesis implants. ${ }^{52}$ Fifty-three of the 129 patients $(41 \%)$ required removal or revision of the prosthesis due to infection, erosion, or mechanical failure with a mean follow-up of 30 months. The Dynaflex $(n=9)$, AMS CX/CXM ( $n=50)$, AMS CX with Inhibizone $(n=17)$, Ambicor $(n=47)$, and Coloplast Mentor $(n=6)$ prostheses were utilized. Total infection rate was $11.9 \%$, which is much higher than non-antibiotic coated implants, and the total protrusion rate was $8.1 \%$. Falcone et al reported on data from a single centre with a 2-stage implantation approach. ${ }^{53}$ An extraperitoneal reservoir was initially placed with the glans sculpture. During the 2nd stage, a dacron envelope was fitted around the proximal and distal tips of the cylinder and anchored to the pubic bone to help prevent protrusion. The overall revision rate was $43 \%$ with mean follow-up of 20 months. However, $88 \%$ of patients were satisfied with the result and $77 \%$ of patients used their device for sexual intercourse. In summary, many experts consider the 3-piece IPP the highest quality option for implantation in the neophallus. ${ }^{47}$ Despite high complication rates and the need for revision, patient satisfaction scores are consistently high.

\section{Safety of Prosthesis Implantation in the Ambulatory Setting}

Traditionally, implantation of penile prosthesis was performed in a hospital setting with 23 hours of observation. However, between the late 1980s and the early 1990s, surgeons started to show that IPP implantation can be safely and effectively performed in an outpatient setting. ${ }^{54-56}$ Mulhall and Bloom compared outcomes between inpatient and outpatient penile prosthesis surgery. ${ }^{27}$ They found similar intra-operative blood loss, operative time, and complication rates between the two settings. Furthermore, they noted significant cost savings by performing the procedure in the outpatient setting. Due to similar complication rates and lower costs associated with outpatient penile implants, national trends have showed decreasing rates of hospital-based IPP surgeries. ${ }^{57-60}$ Theses studies show that by 2010, more than 
$80 \%$ of IPP placements were performed in the ambulatory setting. Although there is no consensus, patients who have more comorbidities were more likely to be performed in the inpatient setting given their increased risk for post-operative complications. ${ }^{59}$ Segal et al proposed a number of comorbidities that would exclude patients from having their prosthesis performed in an outpatient setting. ${ }^{61}$ Patients with comorbidities that increased anesthetic risk such as history of difficult intubation, severe pulmonary disease, BMI $>50$, OSA, severe cardiac diseases, recent coronary stent placement, precluded them from having their surgery in an outpatient setting.

\section{Efficacy}

An ideal penile prosthesis should mimic the biomechanics of a natural erection and be able to provide sufficient rigidity for penetrative sex. Furthermore, the ideal prosthesis should be cosmetically appealing and be easily concealable. Therefore, the scrotal pump and prosthesis tubing should not be physically visible, and there should not be any physical deformity of the cylinders. Placement of a penile prosthesis should also not affect penile skin sensation, orgasms, urination, or ejaculation. Design improvements over the years have significantly improved the reliability and biomimicry of the device. Introduction of the triple layered Dacron and Lycra layers in AMS models and the polyurethane material in the Coloplast prosthesis increased cylinder rigidity and decreased rates of cylinder aneurysms. ${ }^{62}$ Improvements to pump design made inflating and deflating the implant easier for patients. Overall improvements in implant design have improved the reliability and efficacy of the IPP and improved overall patient satisfaction.

\section{Biomechanical Efficacy}

A normal physiologic erection can be characterized by its axial and radial rigidity. Physiologic penile hemodynamic and structural analysis has shown that axial rigidity increases with increasing intracavernosal pressure. ${ }^{63}$ Furthermore, the axial rigidity is dependent on the maximal cavernosal volume at relatively low intracavernosal pressures, tunical distensibility, penile geometry, and the penile diameter-to-length ratio. ${ }^{63}$ Radial rigidity increases with intracavernosal pressures to a finite maximum value, determined mainly by tunical surface wall tension properties. ${ }^{64}$ Studies have shown that axial rigidity is what determines the ability to perform penetrative sex and pelvic thrusting without buckling. ${ }^{62}$ Goldstein et al reported that the average axial force necessary for vaginal penetration was 900 grams (or 8.8 Newtons of force) ${ }^{63}$ Similar to a physiologic erection, the efficacy of an erection produced by an IPP also depends on its axial rigidity ${ }^{65}$ Ansari et al assessed the axial rigidity of IPPs in 100 patients via rigidometry. ${ }^{65}$ They found that digital inflection rigidometer scores correlated with patient satisfaction. Digital inflection rigidometer scores were 710, 842, 872 in unsatisfied patients with the Ambicor, AMS CX700, and Coloplast Titan, respectively. Scovell et al compared the biomechanical properties of the AMS 700 LGX against the Coloplast Titan prosthesis. ${ }^{66}$ They found that the AMS 700 LGX kinked at lower pressures (0.7-1.5 pound-force) compared to the Titan (1.7-2.2 pound-force) at 10, 15, 20 PSIs of fill pressure at both 18 and $22 \mathrm{~cm}$ length cylinders. Furthermore, they found less variability in kink pressure with lower implant fill pressures in the Titan implant, representing improved axial rigidity in real-world situations. In another study by Romo et al, the length and girth of the AMS LGX, CX, CXR and Coloplast Titan Touch were measured as they were filled. ${ }^{67}$ At $22 \mathrm{cc}$ of saline, the $18 \mathrm{~cm}$ length Titan touch had a girth of $17.8 \mathrm{~mm}$ compared to $15.6 \mathrm{~mm}$ for the AMS LGX and $16.5 \mathrm{~mm}$ for the CX. The AMS 700 LGX increased in length by $13 \mathrm{~mm}$ from baseline. The Titan and CXR both had higher rigidity and required more force to reach $50 \%$ compression. In another study by Wallen et al, the AMS LGX, CX and Coloplast Titan were compared with similar performance at maximum fill. ${ }^{68}$ However, at less than maximal inflation, the LGX was unable to withstand the 900 grams (or 8.8 Newtons of force) of pressure shown necessary for penetrative sex. The Titan had slightly better radial rigidity than the LGX and CX. Bending stiffness via 3-point flexure testing showed greater rigidity in the AMS CX at shorter cylinder lengths and greater rigidity in the Titan at longer cylinder lengths. ${ }^{68}$ The Titan also had better results in patients with Peyronie's disease (PD). The increased radial rigidity seen in the Titan is likely secondary to the increased tensile strength of the polyurethane material. A laboratory study by Thirumavalavan et al evaluated the effects of rear tip extenders (RTE) on prosthesis rigidity. ${ }^{69}$ They found that the use of longer RTE resulted in more significant bending deflection. Furthermore, the pseudocapsule around the non-expanding RTE can dilate over time leading to a less stable erection. ${ }^{70}$ 


\section{Patient and Partner Satisfaction}

In patients with ED refractory to conservative therapies, penile prosthesis is an excellent option, and long-term data have shown excellent patient satisfaction rates ranging from $75 \%$ to $100 \%{ }^{71}$ The two most commonly utilized validated questionnaires to evaluate patient satisfaction after penile prosthesis surgery are the International Index of Erectile Function (IIEF) and the Erectile Dysfunction Inventory of Treatment Satisfaction (EDITS). ${ }^{72}$ The IIEF includes 15 questions assessing erectile function, orgasmic function, sexual desire, intercourse satisfaction, and overall satisfaction. EDITS includes 11 questions and was developed to access patient and partner satisfaction after ED treatment. Both IIEF and EDITS were not designed to evaluate patient satisfaction following implantation of penile prosthesis. However, without a validated questionnaire dedicated specifically to the evaluation of satisfaction following penile prosthesis implant, many investigators have utilized IIEF and EDITS as a proxy. Others have proposed their own questionnaires for evaluation of satisfaction following penile prosthesis, but these questionnaires have not been validated. ${ }^{73}$ Recently, Salter et al developed the Satisfaction Survery for Inflatable Penile Implant (SSIPI). ${ }^{74}$ The 16 -item SSIPI had internal consistency, test-retest reliability and convergent and discriminant validity. The SSIPI is the first English questionnaire that has been validated to assess patient satisfaction following penile prosthesis placement. This may allow for a more accurate assessment of patient and partner satisfaction following penile prosthesis implantation.

In a study evaluating patient satisfaction of the semirigid prosthesis, $86.4 \%$ of patients $(n=22)$ and $52.6 \%$ of partners were satisfied by the AMS Spectra. ${ }^{75}$ IIEF scores improved from 28.5 preoperatively to 53.9 at 12 months follow-up. EDITS scores were 45.2 at 12 months follow-up. The authors concluded that the semirigid penile prosthesis had a high degree of patient satisfaction and was also cheaper than the inflatable counterpart. In another study comparing inflatable penile prosthesis to semirigid penile prosthesis, patient satisfaction scores utilizing EDITS were higher in the IPP group (78 \pm 11 ) compared to the semirigid group $(57 \pm 8) .{ }^{76}$ Similarly, partners of these patients were more satisfied with the IPP (72 \pm 10$)$ compared to the semirigid prosthesis $(49 \pm 7)$.

Evaluation of the two-piece IPP also showed high patient satisfaction scores. In a study of 131 men who underwent placement of a 2-piece Ambicor IPP, overall patient and partner satisfaction rates were $96.4 \%$ and $91.2 \%$, respectively. Of the patients who completed the EDITS questionnaire, $90.6 \%$ of patients and $82.6 \%$ of partners were either very satisfied or satisfied overall with the implant. In a similar study of 101 patients who received an Ambicor 2-piece IPP and completed satisfaction questionnaires, the overall patient and partner satisfaction were $85 \%$ and $76 \%$, respectively. ${ }^{16}$ Of these patients, $84 \%$ stated that the implant provided good to excellent rigidity and $86 \%$ would recommend the prosthesis to a friend or undergo the same procedure again. However, in a comparison of axial rigidity between the various implants, the Ambicor prosthesis had lower axial rigidity compared to the 3-piece implants and thus also had lower patient satisfaction scores. ${ }^{65}$

The three-piece IPP is the most common penile implant due to its high overall satisfaction rates, high axial rigidity, and its natural cosmetic appearance. In a retrospective series of 80 patients who had placement of the AMS $700 \mathrm{CX}$ and CXR, long-term follow-up showed high patient satisfaction. ${ }^{77}$ Of these patients, $91 \%$ of patients were able to cycle the device and engage in penetrative sexual activity. Median postoperative IIEF-5 and EDITS scores were 21.5 and 73.1, respectively. Similar to the AMS implants, the Coloplast Titan has high patient satisfaction rates. Lindeborg et al reported an $85 \%$ and $72 \%$ overall satisfaction rate in patients and their partners, respectively. ${ }^{78}$ In a comparison of satisfaction rates between the AMS CX700 and the Coloplast Titan, Otero et al showed high overall satisfaction in both groups. No patients $(n=248)$ were dissatisfied with either implant. ${ }^{79}$ The authors did note that more patients were overall very satisfied with the CX700 (71\%) compared to the Titan (44\%, p < 0.0001). On the other hand, roughly 10\% of patients required 6 or more months to be able to learn how to manage the prosthesis (compared to $0 \%$ in patients with the Titan OTR). More than $25 \%$ of patients with the Titan were either dissatisfied or very dissatisfied with the ease of deflating the prosthesis compared to $4 \%$ in the CX700. More than $90 \%$ of partners thought sexual intercourse was good or very good in both implant models. However, more partners would strongly recommend the surgery again in the CX700 (69\%) compared to the Titan (56\%). In another study comparing the CX700 with the Titan prosthesis, there was no difference in EDITS score with a mean follow-up time of 58 months $(\mathrm{n}=55) .{ }^{80}$ 


\section{Conclusion}

Over the past few decades, the penile prosthesis has evolved significantly. Design modifications have greatly improved its safety and reliability. Development of improved surgical techniques has decreased intraoperative injuries and reservoir-related complications. Development of antibiotic coated penile implants has significantly decreased infection rates. Despite advancements in implant design, mechanical failure can still occur over time and can require surgical revision. Both two-piece and three-piece inflatable penile prostheses have high overall patient and partner satisfaction rates. Each brand of IPP has its advantages and disadvantages and can produce excellent clinical outcomes in the appropriately selected patient. With its high overall satisfaction rates and efficacy and low associated complications, the inflatable penile prosthesis remains an excellent option for patients with erectile dysfunction. In the future, there will be further design improvements including other IPP models and electronic IPPs, which would allow for control of inflation/ deflation remotely with a smartphone app.

\section{Disclosure}

Dr Laurence A Levine is a consultant/instructor for Boston Scientific, outside the submitted work. The authors report no other conflicts of interest in this work.

\section{References}

1. Feldman HA, Goldstein I, Hatzichristou DG, Krane RJ, McKinlay JB. Impotence and its medical and psychosocial correlates: results of the Massachusetts Male Aging Study. J Urol. 1994;151(1):54-61. doi:10.1016/S0022-5347(17)34871-1

2. Shamloul R, Ghanem H. Erectile dysfunction. Lancet. 2013;381(9861):153-165. doi:10.1016/S0140-6736(12)60520-0

3. Hakky TS, Wang R, Henry GD. The evolution of the inflatable penile prosthetic device and surgical innovations with anatomical considerations. Curr Urol Rep. 2014;15(6):410. doi:10.1007/s11934-014-0410-9

4. Schultheiss D, Gabouev AI, Jonas U. Nikolaj A. Bogoraz (1874-1952): pioneer of phalloplasty and penile implant surgery. J Sex Med. 2005;2 (1):139-146. doi:10.1111/j.1743-6109.2005.20114.x

5. Le B, Burnett AL. Evolution of penile prosthetic devices. Korean J Urol. 2015;56(3):179-186. doi:10.4111/kju.2015.56.3.179

6. Rodriguez KM, Pastuszak AW. A history of penile implants. Transl Androl Urol. 2017;6(Suppl 5):S851-S857. doi:10.21037/tau.2017.04.02

7. Scott FB, Bradley WE, Timm GW. Management of erectile impotence. Use of implantable inflatable prosthesis. Urology. 1973;2(1):80-82. doi:10.1016/0090-4295(73)90224-0

8. O'Rourke TK, Erbella A, Zhang Y, Wosnitzer MS. Prevention, identification, and management of post-operative penile implant complications of infection, hematoma, and device malfunction. Transl Androl Urol. 2017;6(Suppl 5):S832-S848. doi:10.21037/tau.2017.06.07

9. Mulcahy JJ. The prevention and management of noninfectious complications of penile implants. Sex Med Rev. 2015;3(3):203-213. doi:10.1002/ smrj.41

10. Levine LA, Becher EF, Bella AJ, et al. Penile prosthesis surgery: current recommendations from the international consultation on sexual medicine. $J$ Sex Med. 2016;13(4):489-518. doi:10.1016/j.jsxm.2016.01.017

11. Sexton SJ, Granieri MA, Lentz AC. Survey on the contemporary management of intraoperative urethral injuries during penile prosthesis implantation. $J$ Sex Med. 2018;15(4):576-581. doi:10.1016/j.jsxm.2018.01.026

12. Levine LA, Hoeh MP. Review of penile prosthetic reservoir: complications and presentation of a modified reservoir placement technique. $J$ Sex Med. 2012;9(11):2759-2769. doi:10.1111/j.1743-6109.2012.02807.x

13. Abbosh PH, Thom MR, Bullock A. Laparoscopic capsulotomy to treat autoinflation of inflatable penile prostheses. J Sex Med. 2012;9 (4):1212-1215. doi:10.1111/j.1743-6109.2011.02525.x

14. Levine LA, Estrada CR, Morgentaler A. Mechanical reliability and safety of, and patient satisfaction with the Ambicor inflatable penile prosthesis: results of a 2 center study. $J$ Urol. 2001;166(3):932-937. doi:10.1016/S0022-5347(05)65867-3

15. Henry GD, Karpman E, Brant W, et al. The who, how and what of real-world penile implantation in 2015: the PROPPER registry baseline data. J Urol. 2016;195(2):427-433. doi:10.1016/j.juro.2015.07.109

16. Lux M, Reyes-Vallejo L, Morgentaler A, Levine LA. Outcomes and satisfaction rates for the redesigned 2-piece penile prosthesis. $J$ Urol. 2007 ; 177 (1):262-266. doi:10.1016/j.juro.2006.08.094

17. Simon DP, Alter K, Bajic P, Levine LA. Device profile of the Ambicor two-piece inflatable penile prosthesis for treatment of erectile dysfunction: overview of its safety and efficacy. Expert Rev Med Devices. 2021;18(1):9-14. doi:10.1080/17434440.2021.1853524

18. Abdelsayed GA, Levine LA. Ambicor 2-piece inflatable penile prosthesis: who and how? J Sex Med. 2018;15(3):410-415. doi:10.1016/j. jsxm.2017.12.010

19. Trost L, Hellstrom WJ. History, contemporary outcomes, and future of penile prostheses: a review of the literature. Sex Med Rev. 2013;1 (3): $150-163$. doi: $10.1002 /$ smrj.8

20. Sharma D, Smith RP. Troubleshooting intraoperative complications of penile prosthesis placement. Transl Androl Urol. 2017;6(Suppl 5):S892S897. doi:10.21037/tau.2017.07.13

21. Kavoussi NL, Hofer MD, Viers BR, et al. Synchronous ipsilateral high submuscular placement of prosthetic balloons and reservoirs. $J$ Sex Med. 2017;14(2):264-268. doi:10.1016/j.jsxm.2016.12.001

22. Hernandez JC, Trost L, Kohler T, et al. Emerging complications following alternative reservoir placement during inflatable penile prosthesis placement: a 5-year multi-institutional experience. J Urol. 2019;201(3):581-586. doi:10.1016/j.juro.2018.10.013 
23. Capoccia EM, Phelps JN, Levine LA. Modified inflatable penile prosthesis reservoir placement into space of retzius: comparing outcomes in men with or without prior pelvic surgery. $J$ Sex Med. 2017;14(7):968-973. doi:10.1016/j.jsxm.2017.05.002

24. Eid JF, Wilson SK, Cleves M, Salem EA. Coated implants and "no touch" surgical technique decreases risk of infection in inflatable penile prosthesis implantation to $0.46 \%$. Urology. 2012;79(6):1310-1315. doi:10.1016/j.urology.2011.11.076

25. Mulcahy JJ, Carson CC. Long-term infection rates in diabetic patients implanted with antibiotic-impregnated versus nonimpregnated inflatable penile prostheses: 7-year outcomes. Eur Urol. 2011;60(1):167-172. doi:10.1016/j.eururo.2011.01.046

26. Carson CC. Efficacy of antibiotic impregnation of inflatable penile prostheses in decreasing infection in original implants. $J$ Urol. 2004;171 (4):1611-1614. doi:10.1097/01.ju.0000118245.66976.e1

27. Mulhall JP, Bloom K. Comparison of in-patient and out-patient penile prosthesis surgery. Int J Impot Res. 2001;13(5):251-254. doi:10.1038/sj. ijir.3900695

28. Ehlers M, McCormick B, Coward RM, Figler BD. Innovating incrementally: development of the modern inflatable penile prosthesis. Curr Urol Rep. 2019;20(4):17. doi:10.1007/s11934-019-0880-x

29. Wolter CE, Hellstrom WJ. The hydrophilic-coated inflatable penile prosthesis: 1-year experience. J Sex Med. 2004;1(2):221-224. doi:10.1111/ j.1743-6109.2004.04032.x

30. Wilson SK, Zumbe J, Henry GD, Salem EA, Delk JR, Cleves MA. Infection reduction using antibiotic-coated inflatable penile prosthesis. Urology. 2007;70(2):337-340. doi:10.1016/j.urology.2007.03.058

31. Carson CC, Mulcahy JJ, Harsch MR. Long-term infection outcomes after original antibiotic impregnated inflatable penile prosthesis implants: up to 7.7 years of followup. J Urol. 2011;185(2):614-618. doi:10.1016/j.juro.2010.09.094

32. Bettocchi C, Ditonno P, Palumbo F, et al. Penile prosthesis: what should we do about complications? Adv Urol. 2008;2008:573560.

33. Mulcahy JJ. Long-term experience with salvage of infected penile implants. J Urol. 2000;163(2):481-482. doi:10.1016/S0022-5347(05)67906-2

34. Kim DS, Yang KM, Chung HJ, Choi HM, Choi YD, Choi HK. AMS 700CX/CXM inflatable penile prosthesis has high mechanical reliability at long-term follow-up. J Sex Med. 2010;7(7):2602-2607. doi:10.1111/j.1743-6109.2010.01801.x

35. Wilson SK, Delk JR, Salem EA, Cleves MA. Long-term survival of inflatable penile prostheses: single surgical group experience with 2384 first-time implants spanning two decades. J Sex Med. 2007;4(4 Pt 1):1074-1079. doi:10.1111/j.1743-6109.2007.00540.x

36. Chung E, Van CT, Wilson I, Cartmill RA. Penile prosthesis implantation for the treatment for male erectile dysfunction: clinical outcomes and lessons learnt after 955 procedures. World J Urol. 2013;31(3):591-595. doi:10.1007/s00345-012-0859-4

37. Wintner A, Lentz AC. Inflatable penile prosthesis: considerations in revision surgery. Curr Urol Rep. 2019;20(4):18. doi:10.1007/s11934-019-0881-9

38. Cefalu CA, Deng X, Zhao LC, Scott JF, Mehta S, Morey AF. Safety of the "drain and retain" option for defunctionalized urologic prosthetic balloons and reservoirs during artificial urinary sphincter and inflatable penile prosthesis revision surgery: 5-year experience. Urology. 2013;82 (6):1436-1439. doi:10.1016/j.urology.2013.07.038

39. Madiraju SK, Hakky TS, Perito PE, Wallen JJ. Placement of inflatable penile implants in patients with prior radical pelvic surgery: a literature review. Sex Med Rev. 2019;7(1):189-197. doi:10.1016/j.sxmr.2018.10.002

40. Horenblas S, Meinhardt W, Ijzerman W, Moonen LF. Sexuality preserving cystectomy and neobladder: initial results. J Urol. 2001;166(3):837-840. doi:10.1016/S0022-5347(05)65847-8

41. Meinhardt W, Horenblas S. Sexuality preserving cystectomy and neobladder (SPCN): functional results of a neobladder anastomosed to the prostate. Eur Urol. 2003;43(6):646-650. doi:10.1016/S0302-2838(03)00099-X

42. Lane BR, Abouassaly R, Angermeier KW, Montague DK. Three-piece inflatable penile prostheses can be safely implanted after radical prostatectomy through a transverse scrotal incision. Urology. 2007;70(3):539-542. doi:10.1016/j.urology.2007.04.009

43. Menard J, Tremeaux JC, Faix A, Pierrevelcin J, Staerman F. Erectile function and sexual satisfaction before and after penile prosthesis implantation in radical prostatectomy patients: a comparison with patients with vasculogenic erectile dysfunction. J Sex Med. 2011;8(12):3479-3486. doi:10.1111/j.1743-6109.2011.02466.x

44. Loh-Doyle J, Patil MB, Sawkar H, Wayne K, Boyd SD. 3-piece inflatable penile prosthesis placement following radical cystoprostatectomy and urinary diversion: technique and outcomes. J Sex Med. 2018;15(6):907-913. doi:10.1016/j.jsxm.2018.01.014

45. Kim JK, Cho MC, Ku JH, Paick JS. Preperitoneal placement of an inflatable penile prosthesis reservoir for postoperative erectile dysfunction after radical cystoprostatectomy with orthotopic neobladder. Investig Clin Urol. 2016;57(5):364-366. doi:10.4111/icu.2016.57.5.364

46. Loh-Doyle JC. Penile implant considerations in the bladder cancer survivor. Curr Urol Rep. 2019;20(2):7. doi:10.1007/s11934-019-0873-9

47. Polchert M, Dick B, Raheem O. Narrative review of penile prosthetic implant technology and surgical results, including transgender patients. Transl Androl Urol. 2021;10(6):2629-2647. doi:10.21037/tau-20-1279

48. Levine LA, Zachary LS, Gottlieb LJ. Prosthesis placement after total phallic reconstruction. J Urol. 1993;149(3):593-598. doi:10.1016/S00225347(17)36158-X

49. Blewniewski M, Ostrowski I, Pottek T, et al. Safety and efficacy outcomes of ZSI 475 penile prosthesis. Urologia. 2017;84(2):98-101. doi:10.5301/ uj. 5000240

50. Puckett CL, Montie JE. Construction of male genitalia in the transsexual, using a tubed groin flap for the penis and a hydraulic inflation device. Plast Reconstr Surg. 1978;61(4):523-530. doi:10.1097/00006534-197804000-00005

51. Zuckerman JM, Smentkowski K, Gilbert D, et al. Penile prosthesis implantation in patients with a history of total phallic construction. J Sex Med. 2015;12(12):2485-2491. doi:10.1111/jsm.13067

52. Hoebeke PB, Decaestecker K, Beysens M, Opdenakker Y, Lumen N, Monstrey SM. Erectile implants in female-to-male transsexuals: our experience in 129 patients. Eur Urol. 2010;57(2):334-340. doi:10.1016/j.eururo.2009.03.013

53. Falcone M, Garaffa G, Gillo A, Dente D, Christopher AN, Ralph DJ. Outcomes of inflatable penile prosthesis insertion in 247 patients completing female to male gender reassignment surgery. BJU Int. 2018;121(1):139-144. doi:10.1111/bju.14027

54. Garber BB. Outpatient inflatable penile prosthesis insertion. Urology. 1997;49(4):600-603. doi:10.1016/S0090-4295(96)00540-7

55. Lubensky JD. Outpatient 3-piece inflatable penile prosthesis. J Urol. 1991;145(6):1176-1177. doi:10.1016/S0022-5347(17)38566-X

56. Scott FB. Outpatient implantation of penile prostheses under local anesthesia. Urol Clin North Am. 1987;14(1):177-185. doi:10.1016/S00940143(21)00831-4

57. Mirheydar HS, Palazzi KL, Parsons JK, Chang D, Hsieh TC. Hospital-based trends in penile prosthetic surgery. J Sex Med. 2015;12(4):1092-1098. doi:10.1111/jsm.12829 
58. Oberlin DT, Matulewicz RS, Bachrach L, Hofer MD, Brannigan RE, Flury SC. National practice patterns of treatment of erectile dysfunction with penile prosthesis implantation. $J$ Urol. 2015;193(6):2040-2044. doi:10.1016/j.juro.2014.11.095

59. Alwaal A, Harris CR, Hussein AA, et al. The decline of inpatient penile prosthesis over the 10-year period, 2000-2010. Sex Med. 2015;3 (4):280-286. doi:10.1002/sm2.82

60. Lee DJ, Najari BB, Davison WL, et al. Trends in the utilization of penile prostheses in the treatment of erectile dysfunction in the United States. $J$ Sex Med. 2015;12(7):1638-1645. doi:10.1111/jsm.12921

61. Segal RL, Siegelbaum MH, Lerner BD, Weinberg AC. Inflatable penile prosthesis implantation in the ambulatory setting: a systematic review. Sex Med Rev. 2020;8(2):338-347. doi:10.1016/j.sxmr.2019.07.006

62. Madiraju SK, Wallen JJ, Rydelek SP, Carrion RE, Perito PE, Hakky TS. biomechanical studies of the inflatable penile prosthesis: a review. Sex Med Rev. 2019;7(2):369-375. doi:10.1016/j.sxmr.2018.11.006

63. Goldstein I, Udelson D. Axial penile rigidity: determinants and relation to hemodynamic parameters. Int J Impot Res. 1998;10(Suppl 2):S28-S33; discussion S49-S51.

64. Udelson D, Park K, Sadeghi-Nejad H, Salimpour P, Krane RJ, Goldstein I. Axial penile buckling forces vs Rigiscan radial rigidity as a function of intracavernosal pressure: why Rigiscan does not predict functional erections in individual patients. Int J Impot Res. 1999;11(6):327-337; discusion 337-329. doi:10.1038/sj.ijir.3900443

65. Al Ansari A, Talib RA, Canguven O, Shamsodini A. Axial penile rigidity influences patient and partner satisfaction after penile prosthesis implantation. Arch Ital Urol Androl. 2013;85(3):138-142. doi:10.4081/aiua.2013.3.138

66. Scovell JM, Ge L, Barrera EV, Wilson SK, Carrion RE, Hakky TS. Longitudinal and horizontal load testing of inflatable penile implant cylinders of two manufacturers: an ex vivo demonstration of inflated rigidity. J Sex Med. 2016;13(11):1750-1757. doi:10.1016/j.jsxm.2016.09.015

67. Barboglio Romo P, Chikkatur HP, Beldona S, Yi Y, Bruns TM, Malaeb BS. Comparative evaluation of physical characteristics of different inflatable penile prostheses. Scand J Urol. 2017;51(5):420-425. doi:10.1080/21681805.2017.1339292

68. Wallen JJ, Barrera EV, Ge L, et al. Biomechanical comparison of inflatable penile implants: a cadaveric pilot study. J Sex Med. 2018;15 (7):1034-1040. doi:10.1016/j.jsxm.2018.05.014

69. Thirumavalavan N, Cordon BH, Gross MS, Taylor J, Eid JF. Rear tip extenders and penile prosthesis rigidity: a laboratory study of coloplast prostheses. J Sex Med. 2018;15(7):1030-1033. doi:10.1016/j.jsxm.2018.05.001

70. Thirumavalavan N, Cordon BH, Gross MS, Taylor J, Eid JF. The rear tip extender for inflatable penile prostheses: introduction of "Rigidity Factor" and review of the literature. Sex Med Rev. 2019;7(3):516-520. doi:10.1016/j.sxmr.2018.11.001

71. Trost LW, McCaslin R, Linder B, Hellstrom WJ. Long-term outcomes of penile prostheses for the treatment of erectile dysfunction. Expert Rev Med Dev. 2013;10(3):353-366. doi:10.1586/erd.12.92

72. Akakpo W, Pineda MA, Burnett AL. Critical analysis of satisfaction assessment after penile prosthesis surgery. Sex Med Rev. 2017;5(2):244-251. doi:10.1016/j.sxmr.2017.01.001

73. Bhojwani AG, Jain S, Kockelbergh RC, Terry T. Sexual satisfaction after penile prosthesis insertion for the treatment of erectile dysfunction. Sexual Dysfunction. 1998;1:133-136. doi:10.1046/j.1460-2679.1998.00038.x

74. Salter CA, Bach PV, Jenkins L, et al. Development and validation of the satisfaction survey for inflatable penile implant (SSIPI). J Sex Med. 2021;18(9):1641-1651. doi:10.1016/j.jsxm.2021.06.020

75. Falcone M, Rolle L, Ceruti C, et al. Prospective analysis of the surgical outcomes and patients' satisfaction rate after the AMS Spectra penile prosthesis implantation. Urology. 2013;82(2):373-376. doi:10.1016/j.urology.2013.04.027

76. Bozkurt IH, Arslan B, Yonguc T, et al. Patient and partner outcome of inflatable and semi-rigid penile prosthesis in a single institution. Int Braz J Urol. 2015;41(3):535-541. doi:10.1590/S1677-5538.IBJU.2014.0241

77. Vitarelli A, Divenuto L, Fortunato F, et al. Long term patient satisfaction and quality of life with AMS700CX inflatable penile prosthesis. Arch Ital Urol Androl. 2013;85(3):133-137. doi:10.4081/aiua.2013.3.133

78. Lindeborg L, Fode M, Fahrenkrug L, Sonksen J. Satisfaction and complications with the Titan(R) one-touch release penile implant. Scand J Urol. 2014;48(1):105-109. doi:10.3109/21681805.2013.808695

79. Otero JR, Cruz CR, Gomez BG, et al. Comparison of the patient and partner satisfaction with 700CX and Titan penile prostheses. Asian J Androl. 2017;19(3):321-325. doi:10.4103/1008-682X.172822

80. Morgado A, Cavadas AS, Pacheco Figueiredo L, Tomada N. Long-term patient-reported satisfaction with different inflatable penile prosthesis: comparison between AMS 700CX and Coloplast Titan. Rev Int Androl. 2018;16(3):112-118. doi:10.1016/j.androl.2017.07.003

Medical Devices: Evidence and Research

Dovepress

\section{Publish your work in this journal}

Medical Devices: Evidence and Research is an international, peer-reviewed, open access journal that focuses on the evidence, technology, research, and expert opinion supporting the use and application of medical devices in the diagnosis, monitoring, treatment and management of clinical conditions and physiological processes. The identification of novel devices and optimal use of existing devices which will lead to improved clinical outcomes and more effective patient management and safety is a key feature of the journal. The manuscript management system is completely online and includes a very quick and fair peer-review system. Visit http://www.dovepress.com/testimonials.php to read real quotes from published authors.

Submit your manuscript here: https://www.dovepress.com/medical-devices-evidence-and-research-journa 